\title{
miR-148a Suppresses estrogen-induced viability and migration of breast cancer cells via inhibition of estrogen receptor $\alpha$ expression
}

\author{
FANG MA ${ }^{1,2}$, YEQIAN FENG ${ }^{2}$, WEIHUI LI ${ }^{1}$, ZEXUAN LI ${ }^{1}$, TIEBANG LIU ${ }^{3}$ and LINGJIANG LI ${ }^{1,3}$ \\ ${ }^{1}$ Mental Health Institute, The Second Xiangya Hospital, National Technology Institute of Psychiatry, Key Laboratory of \\ Psychiatry and Mental Health of Hunan; ${ }^{2}$ Department of Oncology, The Second Xiangya Hospital, Central South University, \\ Changsha, Hunan 410011; ${ }^{3}$ Department of Psychiatry, Shenzhen Kangning Hospital, Shenzhen, Guangdong 518020, P.R. China
}

Received January 12, 2016; Accepted January 20, 2017

DOI: $10.3892 /$ etm.2017.4255

\begin{abstract}
MicroRNAs (miRs) play critical roles in the development and malignant progression of human cancers. miR-148a has previously been found to inhibit the migration and invasion of breast cancer cells. However, the underlying mechanism of miR-148a in regulating the viability and migration of estrogen receptor (ER) $\alpha$-positive breast cancer cells is still unknown. In this study, ER $\alpha$-positive breast cancer MCF7 cells were treated with estradiol (E2). Data from MTT and wound healing assays showed that E2 treatment promoted the viability and migration of MCF7 cells. A bioinformatics analysis and luciferase reporter assay identified ER $\alpha$ as a direct target of miR-148a. Ectopic expression of miR-148a significantly decreased the protein expression of $\mathrm{ER} \alpha(\mathrm{P}<0.01)$, while knockdown of miR-148a significantly increased the ER $\alpha$ protein level in MCF7 cells $(\mathrm{P}<0.01)$. Furthermore, miR-148a overexpression significantly inhibited the E2-induced viability and migration of MCF7 cells $(\mathrm{P}<0.01)$, similar to the effect of silencing ER $\alpha$. However, overexpression of ER $\alpha$ rescued the suppressed viability and migration caused by miR-148a upregulation. Finally, it was found that E2 treatment led to a significant decrease in the miR-148a level in MCF7 cells $(\mathrm{P}<0.01)$. These results suggest that miR-148a can suppress the E2-induced viability and migration of MCF7 breast cancer cells via inhibition of ER $\alpha$ protein expression, expanding the understanding of miR function in ER $\alpha$-positive breast cancer.
\end{abstract}

Correspondence to: Professor Lingjiang Li, Mental Health Institute, The Second Xiangya Hospital, National Technology Institute of Psychiatry, Key Laboratory of Psychiatry and Mental Health of Hunan, Central South University, 139 Renmin Middle Road, Changsha, Hunan 410011, P.R. China

E-mail: 1lj2920@163.com

Key words: breast cancer, microRNA-148a, estrogen, estrogen receptor $\alpha$

\section{Introduction}

Breast cancer is the most common malignant tumor type in females, and the second most common cancer type worldwide (1). It is the leading cause of cancer mortality in women, responsible for $14 \%$ of all cancer-related fatalities $(2,3)$. Notable improvements in the diagnosis and treatment of breast cancer have been made in recent decades, and the mortality rate of this disease has decreased by more than $30 \%(2,3)$. A better understanding of the molecular mechanisms underlying the malignant progression of breast cancer will be beneficial for improving the efficacy of breast cancer treatment strategies (4).

Hormone 17- $\beta$-estradiol (E2), one of the most prevalent endogenous estrogens, has been found to be involved in physiological and pathological processes, including the development and malignant progression of breast cancer (5). E2 functions through activation of estrogen receptor (ER) $\alpha$-mediated signaling pathways, which are involved in the mediation of cell proliferation, differentiation and migration, as well as homeostasis (6-8). Almost $70 \%$ of breast cancers are ER $\alpha$ positive (9), thus ER $\alpha$ has been developed into a therapeutic target for breast cancer $(10,11)$. For instance, tamoxifen is a selective ER modulator and represents the standard treatment for the majority of breast cancer patients (9). However, the regulatory mechanism of $\mathrm{ER} \alpha$ expression in breast cancer is still largely unknown.

MicroRNAs (miRs) are endogenous non-coding RNAs that can suppress gene expression by directly binding to the 3'untranslated region (3'UTR), causing translation inhibition or mRNA degradation (12). They have been demonstrated to play crucial roles in various biological processes, such as cell proliferation, differentiation, apoptosis and migration, as well as tumorigenesis $(13,14)$. Moreover, the development and malignant progression of breast cancer is tightly associated with gene mutation and deregulation, as well as epigenetic mechanisms including miRs $(15,16)$. Previously, downregulation of miR-148a has been implicated in breast cancer $(17,18)$ and found to inhibit the migration and invasion of breast cancer cells $(19,20)$. For instance, Jiang et al recently found that miR-148a suppressed the migration and invasion of breast cancer cells by directly targeting WNT-1 (19). Xue et al reported that miR-148a inhibited the migration of breast 
cancer cells by targeting MMP-13 (20). However, to the best of our knowledge, the exact role of miR-148a in ER $\alpha$-positive breast cancer remains unclear. In the present study, we aimed to reveal the underlying mechanism of miR-148a in mediating E2-induced viability and migration of ER $\alpha$-positive breast cancer cells.

\section{Materials and methods}

Cell culture and E2 treatment. A human embryonic kidney cell line, HEK293 and a human breast cancer cell line, MCF7, were obtained from the Cell Bank of Central South University (Changsha, China). MCF7 cells were cultured in Dulbecco's modified Eagle's medium (DMEM; Thermo Fisher Scientific, Inc., Waltham, MA, USA) with $10 \%$ fetal bovine serum (Thermo Fisher Scientific, Inc.) at $37^{\circ} \mathrm{C}$ with $5 \% \mathrm{CO}_{2}$. MCF7 cells were treated with $\mathrm{E} 2$ for $3 \mathrm{~h}$, then cell viability and migration rates were analyzed.

MTT assay. An MTT assay was used to examine cell viability. MCF7 cells (5,000 per well) were cultured in a 96-well plate. Each well contained $100 \mu \mathrm{l}$ fresh serum-free DMEM with $0.5 \mathrm{~g} / 1 \mathrm{MTT}$. Following an incubation at $37^{\circ} \mathrm{C}$ for $0,12,24$, 48 or $72 \mathrm{~h}$, the medium was removed by aspiration and $50 \mu \mathrm{l}$ dimethyl sulfoxide $(5 \mathrm{mg} / \mathrm{ml}$; Sigma-Aldrich; Merck KGaA, Darmstadt, Germany) was added to each well. After incubation at room temperature for $10 \mathrm{~min}$, formazan production was detected by measuring the optical density at $570 \mathrm{~nm}$ using an AIA 600II Automated Enzyme Immunoassay Analyzer (Tosoh Corporation, Tokyo, Japan).

Wound healing assay. A wound healing assay was used to examine cell migration. MCF7 cells were cultured at $37^{\circ} \mathrm{C}$ with $5 \% \mathrm{CO}_{2}$ to full confluence in 6 -well plates. Wounds of $\sim 1 \mathrm{~mm}$ width were created with a plastic scriber. After that, cells were washed with phosphate-buffered saline (PBS) and incubated at $37^{\circ} \mathrm{C}$ with $5 \% \mathrm{CO}_{2}$ for $48 \mathrm{~h}$. Then, the wounds were observed and photographed under an Eclipse Ti-E inverted microscope (Nikon Corporation, Tokyo, Japan).

Cell transfection. MCF7 cells were transfected with a scrambled miR mimic (Yearthbio, Changsha, China) as a negative control (miR-NC), an miR-148a mimic (Yearthbio), a negative control inhibitor (Yearthbio), an miR-148a inhibitor (Yearthbio), ER $\alpha$ siRNA (Yearthbio) or pcDNA3.1-ER $\alpha$ ORF plasmid (Yearthbio) using Lipofectamine ${ }^{\circledR} 2000$ (Thermo Fisher Scientific, Inc.), in accordance with the manufacturer's protocols. Transfection efficiency was measured using reverse transcription-quantitative polymerase chain reaction (RT-qPCR) and western blotting as follows.

RT-qPCR assay. Total RNA from MCF7 cells was isolated using Trizol reagent (Thermo Fisher Scientific, Inc.), according to the manufacturer's instructions. Total RNA was reverse transcribed using the RevertAid Reverse Transcription kit (Thermo Fisher Scientific, Inc.) according to the manufacturer's instructions. Then, qPCR was conducted using the SYBR-Green miScript PCR kit (Qiagen, Inc., Valencia, CA, USA) and a Roche LightCycler 480 PCR machine (Roche Diagnostics, Basel, Switzerland). All primers were purchased from Sangon Biotech Co., Ltd. (Shanghai, China). The primers for $\mathrm{ER} \alpha$ were: Forward, 5'-CCCACTCAACAGCGTGTC TC-3' and reverse, 5'-CGTCGATTATCTGAATTTGGC CT-3'. The primers for GAPDH were: Forward, 5'-ACAACT TTGGTATCGTGGAAGG-3' and reverse, 5'-GCCATCACG CCACAGTTTC- 3 . The reaction conditions were: $95^{\circ} \mathrm{C}$ for $10 \mathrm{~min}$, followed by $45 \mathrm{cycles}$ of $95^{\circ} \mathrm{C}$ for $15 \mathrm{sec}$ and $60^{\circ} \mathrm{C}$ for $30 \mathrm{sec}$. The relative mRNA expression of ER $\alpha$ was normalized against that of GAPDH. The relative expression of miR-148a was normalized against that of U6. The relative expression was analyzed by the $2^{-\Delta \Delta C q}$ method (21).

Western blot analysis. Cells were lysed using RIPA buffer (Beyotime Institute of Biotechnology, Shanghai, China). The concentration of protein was quantified using the Pierce BCA Protein Assay kit (Thermo Fisher Scientific, Inc.). After that, proteins (50 $\mu \mathrm{g}$ ) were separated using $10 \%$ SDS-PAGE gels (Beyotime Institute of Biotechnology) and blotted onto a polyvinylidene difluoride (PVDF) membrane (Life Technologies, Grand Island, NY, USA), which was then blocked with 5\% non-fat dried milk (Mengniu, Beijing, China) in PBS with Tween (PBST; Beyotime Institute of Biotechnology) overnight at $4^{\circ} \mathrm{C}$. The PVDF membrane was then incubated with rabbit monoclonal anti-human ER $\alpha$ antibody (1:100; ab32063; Abcam, Cambridge, MA, USA), or rabbit monoclonal anti-human GAPDH antibody (1:100; ab9485; Abcam) antibody at room temperature for $3 \mathrm{~h}$. After being washed with PBST three times, the PVDF membrane was incubated with goat anti-rabbit horseradish peroxidase-conjugated secondary antibody (1:5,000; ab7090; Abcam) for 40 min at room temperature. Chemiluminescent detection was performed with an ECL kit (Thermo Fisher Scientific, Inc.). The relative protein expression was determined using Image-Pro plus software version 6.0 (Media Cybernetics, Inc., Rockville, MD, USA), represented as the density ratio vs. GAPDH.

Bioinformatics analysis and luciferase reporter assay. TargetScan 3.1 online software (Whitehead Institute for Biomedical Research, Cambridge, MA, USA) was used to analyze the putative target genes of miR-148a (22).

A wild type (WT)-or mutant type (MT)-ER $\alpha$ 3'UTR was inserted downstream of the luciferase reporter gene in a pMIR-REPORT vector (Yearthbio), generating a WT-ER $\alpha-3$ 'UTR reporter vector or MT-ER $\alpha-3$ 'UTR reporter vector, respectively. HEK293 cells were co-transfected with miR-148a mimic (Yearthbio) or miR-NC (Yearthbio), a WT-ER $\alpha-3$ 'UTR or MT-ER $\alpha-3$ 'UTR reporter vector, and pRL-SV40 (Promega Corporation, Madison, WI, USA) expressing Renilla luciferase using Lipofectamine ${ }^{\circledR} 2000$ according to the manufacturer's protocol. Following incubation at $37^{\circ} \mathrm{C}$ with $5 \% \mathrm{CO}_{2}$ for $48 \mathrm{~h}$, the luciferase activities were measured using the Dual-Luciferase Reporter Assay System (Promega Corporation), according to the manufacturer's instructions.

Statistical analysis. Data are expressed as the mean \pm standard deviation of three independent experiments. The Student's t-test was used to compare differences between two groups. One-way analysis of variance was used to analyze 
differences among more than two groups. Statistical analysis was conducted using SPSS 17.0 software (SPSS, Inc., Chicago, IL, USA) and $\mathrm{P}<0.05$ was considered to indicate a statistically significant difference.

\section{Results}

E2 treatment promotes MCF7 cell viability and migration. It has been well established that MCF7 is an ER $\alpha$-positive breast cancer cell line (23). In the current study, MCF7 were treated with E2 $(1 \mathrm{mM})$ for $3 \mathrm{~h}$, followed by analyses of cell viability and migration. MTT assay data indicated that MCF7 cell viability was significantly increased following treatment with $\mathrm{E} 2$ for $48 \mathrm{~h}(\mathrm{P}<0.05)$ or $72 \mathrm{~h}(\mathrm{P}<0.01)$, as compared with the control group (Fig. 1A). Furthermore, wound healing assay data showed that E2 treatment also upregulated the migration of MCF7 cells at $48 \mathrm{~h}$, when compared to the control group $(\mathrm{P}<0.01$; Fig. 1B). These results suggest that E2 activates $\mathrm{ER} \alpha$-mediated viability- and migration-related signaling pathways in MCF7 cells.

$E R \alpha$ is a direct target of $m i R-148 a$. As the function of E2 is through activation of ER $\alpha$-mediated downstream signaling, a bioinformatics search was conducted for putative miRs that directly target ER $\alpha$. As indicated in Fig. 2A and B, $\mathrm{ER} \alpha$ was predicted to be a direct target of miR-148a, and the targeting relationship was evolutionarily conserved. In order to examine this targeting relationship, the WT- or MT-ER $\alpha-3$ 'UTR was inserted downstream of the luciferase reporter gene in a pMIR-REPORT vector (Fig. 2C and D). A luciferase reporter assay demonstrated that transfection with the miR-148a mimic significantly reduced the luciferase activity in HEK293 cells transfected with WT-ER $\alpha-3$ 'UTR reporter vector, but not in cells transfected with MT-ER $\alpha-3$ 'UTR reporter vector, when compared to the control group $(\mathrm{P}<0.01$; Fig. $2 \mathrm{E})$. These findings indicated that $\mathrm{ER} \alpha$ was a direct target of miR-148a.

miR-148a negatively regulated the protein expression of ER $\alpha$ in MCF7 cells. As miRs most often inhibit the expression of their target genes at the post-transcriptional level, the effects of miR-148a upregulation and downregulation on the protein level of ER $\alpha$ in MCF7 cells were evaluated. MCF7 cells were transfected with miR-NC, miR-148a mimic, NC inhibitor, or miR-148a inhibitor. After transfection, qPCR was used to evaluate the level of miR-148a expression in each group. As indicated in Fig. 3A and B, transfection with an miR-148a mimic significantly increased the level of miR-148a expression, while transfection with an miR-148a inhibitor significantly decreased the level of miR-148a expression in MCF7 cells as compared with the control group $(\mathrm{P}<0.01$ for both).

Next, a western blot analysis was conducted to determine the protein level of ER $\alpha$. Overexpression of miR-148a significantly reduced the level of ER $\alpha$ protein (Fig. 3C), while knockdown of miR-148a significantly increased the level of ER $\alpha$ protein in MCF7 cells, as compared with the control $(\mathrm{P}<0.01$ for both; Fig. 3D). In addition, neither miR-148a upregulation nor downregulation affected the mRNA expression of ER $\alpha$ in MCF7 cells (Fig. 3E and F). These results

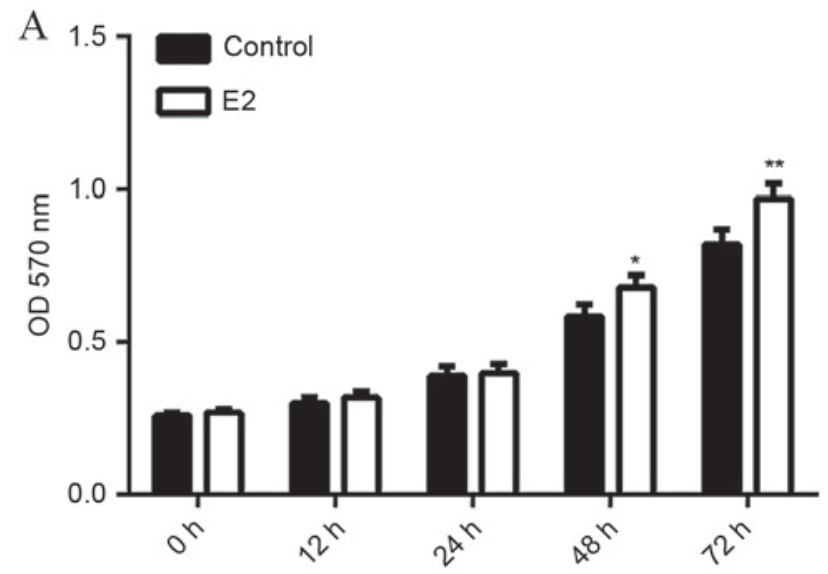

B
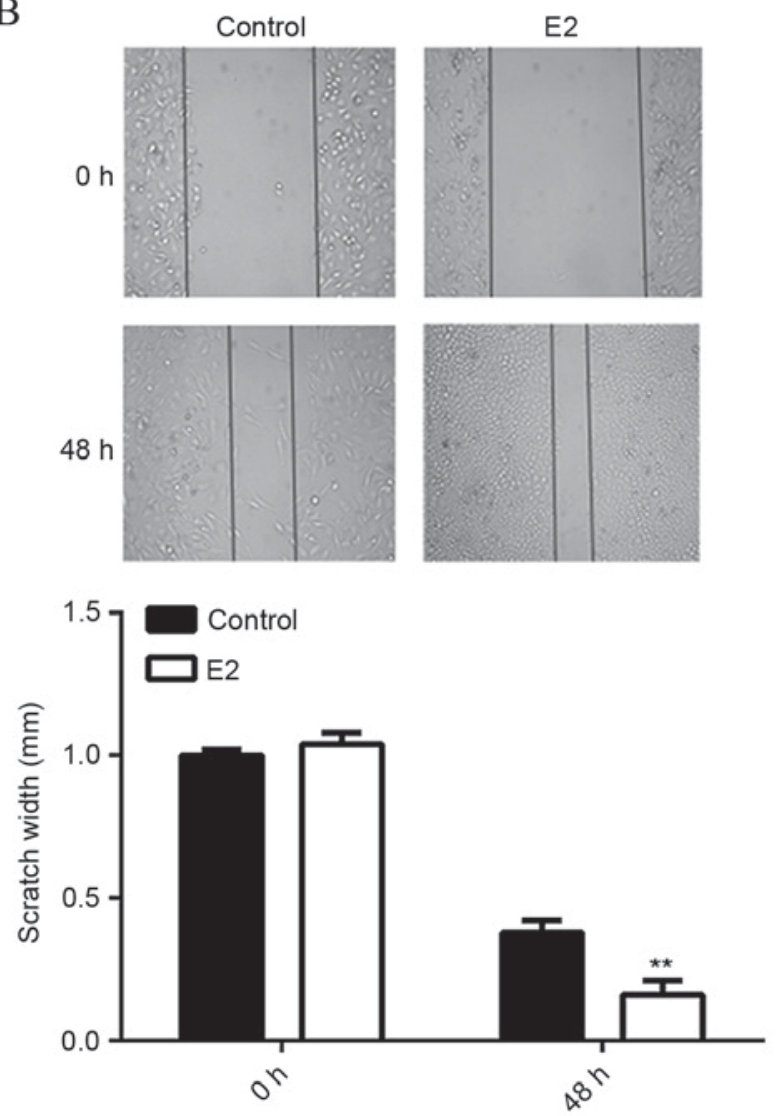

Figure 1. Effect of E2 treatment on MCF7 cell viability and migration. MCF7 cells were treated with $1 \mathrm{mM}$ of E2 for $3 \mathrm{~h}$. (A) MTT assay and (B) wound healing assay were used to evaluate cell viability and migration, respectively. Non-treated MCF7 cells were used as the control. " $\mathrm{P}<0.05$ vs. control, ${ }^{* *} \mathrm{P}<0.01$ vs. control. OD, optical density; E2, estradiol.

suggested that miR-148a negatively regulated the expression of $\mathrm{ER} \alpha$ at the post-transcriptional level in MCF7 cells.

miR-148a overexpression or ER $\alpha$ knockdown inhibits E2-induced MCF7 cell viability and migration. As E2 functions through activation of ER $\alpha$-mediated signaling, it was examined whether miR-148a could affect E2-induced MCF7 cell viability and migration. MCF7 cells with or without miR-148a overexpression were treated with E2 for $3 \mathrm{~h}$. An MTT assay was then used to examine the cell viability in each group. It was found that the viability rate of miR-148a-overexpressing cells was significantly reduced at 48 and $72 \mathrm{~h}$, 


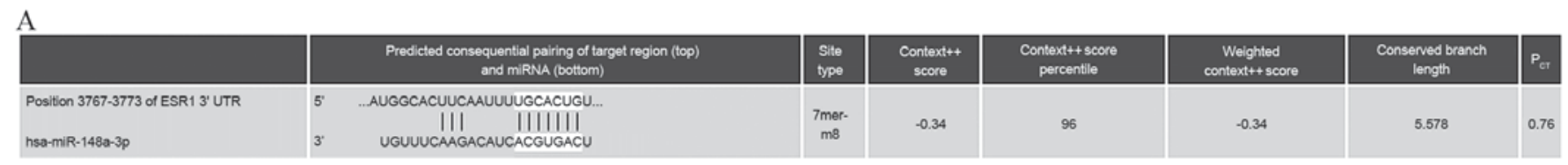

B

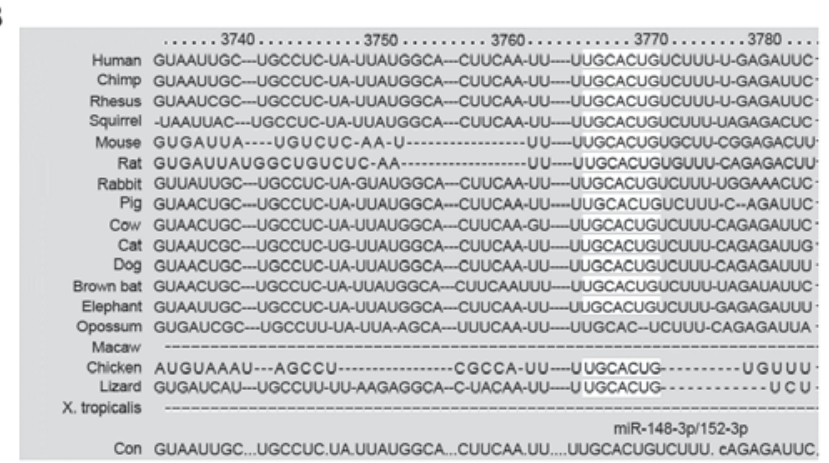

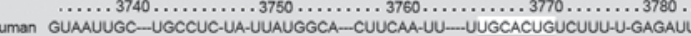
法 RhesUs GUAAUCGC-..-UGCCUC-UA-UUAUGGCA-.-CUUCAA-UU-...UUGCACUGUCUUU-U-GAGAUUC Mouse GUGAUUA-...UGUCUC-AA-U..................UU--UUGCACUGUGCUU-CGGAGACUU PII GUAACUGC..-UGCCUC-UA.UUAUGGCA-..-CUUCAA-UU-...-UUGCACUGUCUUU-C.-AGAUUC. GIN GUAACUGC-UGCCUC-UA-UUAUGGCA-CUUCAA-GU-UUGCACUGUCUUU-CAGAGAUUC DOg GUAACUGC--UGCCUC-UA-UUAUGGCA-CUUCAA-UU-UUUGCACUGUCUUU-CAGAGAUUU 作 . GUGUCAU-WGCCUU-UU-AAGAGGCA-C-UACAA-UU-UUGCACUG-U. miR-148-3p/152-3p

Con GUAAUUGC... UGCCUC. UA.UUAUGGCA...CUUCAA.UU..... UUGCACUGUCUUU. CAGAGAUUC.

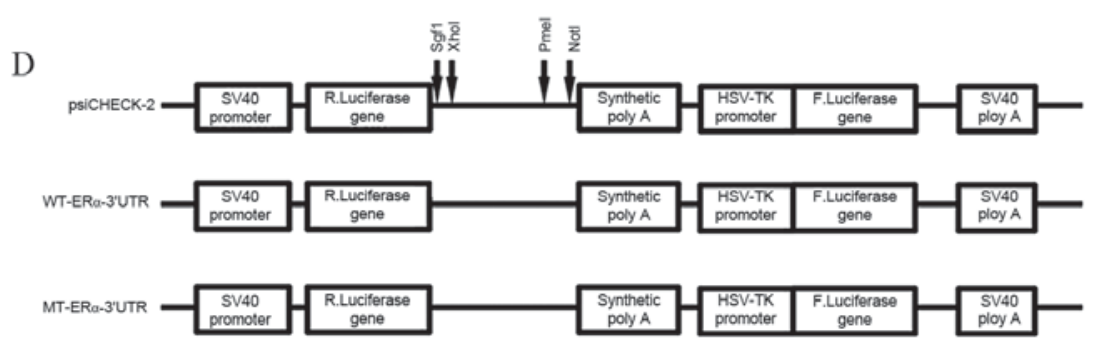

C

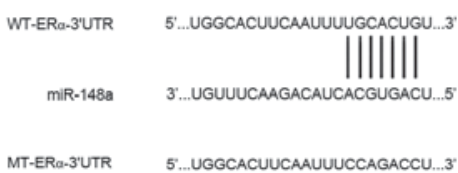

MT-ERo-3'UTR 5. UGGCACUUCAAUUUCCAGACCU...3

E

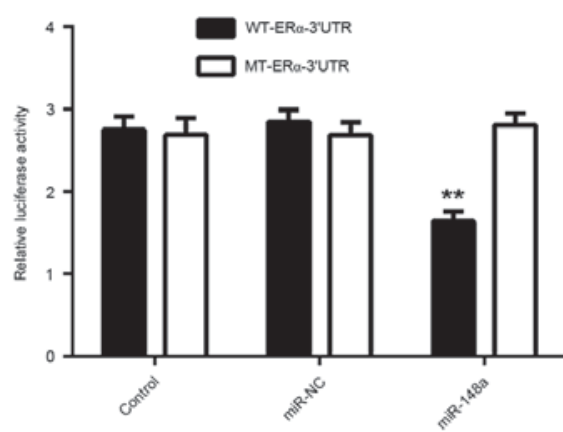

Figure 2. Bioinformatics and luciferase reporter assays to investigate miRNAs involved in ER $\alpha$ signaling pathways. (A and B) TargetScan software predicted that ER $\alpha$ (ESR1) was a target gene of miR-148a, and their targeting relationship was evolutionarily conserved. (C and D) WT or MT ER $\alpha-3^{\prime} \mathrm{UTR}$ was inserted downstream of the luciferase reporter gene in a pMIR-REPORT vector. (E) A luciferase reporter assay following co-transfection of the WT-ER $\alpha-3$ 'UTR or MT-ER $\alpha-3^{\prime}$ UTR reporter vector with an miR-148a mimic or a control miRNA in HEK293 cells. ** $\mathrm{P}<0.01$ vs. control. ER $\alpha$, estrogen receptor $\alpha$; miR, microRNA; WT, wild type; MT, mutant type; 3'UTR, 3'untranslated region; miR-NC, scrambled miR mimic.

as compared with the control group (P<0.01; Fig. 4A). A wound healing assay showed that the scratch width for miR-148a-overexpressing cells was significantly larger at $48 \mathrm{~h}$ compared with the control group, indicating that the migration rate of miR-148a-overexpressing cells was significantly reduced $(\mathrm{P}<0.01$; Fig. 4B).

In order to investigate the underlying mechanism of miR-148a further, MCF7 cells were transfected with ER $\alpha$-specific small interfering RNA (siRNA), which significantly decreased the protein level of ER $\alpha$ as compared with the control $(\mathrm{P}<0.01$; Fig. 4C). MCF7 cells with or without $\mathrm{ER} \alpha$ knockdown were treated with E2 for $3 \mathrm{~h}$. An MTT assay showed that the viability of MCF7 cells was significantly decreased after knockdown of ER $\alpha$ for 48 or $72 \mathrm{~h}$, when compared to the control group $(\mathrm{P}<0.01$; Fig. 4D). A wound healing assay showed that the scratch width for MCF7 ER $\alpha$-knockdown cells was significantly larger at $48 \mathrm{~h}$ compared with the control group, indicating that the migration rate of MCF7 cells was significantly decreased after knockdown of $\mathrm{ER} \alpha(\mathrm{P}<0.01$; Fig. 4E). These results suggest that both miR-148a overexpression and ER $\alpha$ knockdown result in suppressed E2-induced viability and migration of MCF7 cells.

miR-148a inhibits E2-induced MCF7 cell viability and migration via inhibition of ER $\alpha$ expression. In order to investigate whether the effects of miR-148a on E2-induced MCF7 cell viability and migration were through directly targeting ER $\alpha$, MCF7 cells were co-transfected with miR-148a mimic and
ER $\alpha$ ORF plasmid. A western blot analysis showed that the protein level of ER $\alpha$ was significantly higher in cells co-transfected with miR-148a mimic and ER $\alpha$ ORF plasmid, when compared with cells transfected with miR-148a mimic alone $(\mathrm{P}<0.01$; Fig. 5A). This indicated that transfection with $\mathrm{ER} \alpha$ ORF plasmid rescued the suppressive effect of miR-148 on the protein expression of ER $\alpha$ in MCF7 cells. Next, MCF7 cells in each group were treated with E2 for $3 \mathrm{~h}$, and MTT and wound healing assays were performed. The viability of MCF7 cells was significantly increased in cells at 24, 48 and $72 \mathrm{~h}$ after co-transfection with miR-148a mimic and ER $\alpha$ ORF plasmid, as compared with miR-148a-overexpressing cells without plasmid $(\mathrm{P}<0.01$; Fig. 5B). In a wound healing assay, the scratch width of MCF7 cells at $48 \mathrm{~h}$ after co-transfection with miR-148a and ER $\alpha$ ORF plasmid was significantly smaller compared with miR-148a-overexpressing cells without plasmid, indicating that the migration rate of was significantly increased $(\mathrm{P}<0.01$; Fig. 5C). These results suggest that miR-148a inhibits E2-induced MCF7 cell viability and migration via inhibition of ER $\alpha$ expression.

E2 treatment decreases the expression of miR-148a in MCF7 cells. The effect of E2 treatment on the expression of miR-148a in MCF7 cells was examined using qPCR. It was found that E2 treatment decreased the miR-148a levels in MCF7 cells in a dose-dependent manner (Fig. 6). A dosage of $1 \mathrm{mM}$ significantly reduced miR-148a expression as compared with the control $(\mathrm{P}<0.01)$. Furthermore, a dosage of $10 \mathrm{mM}$ significantly 
A

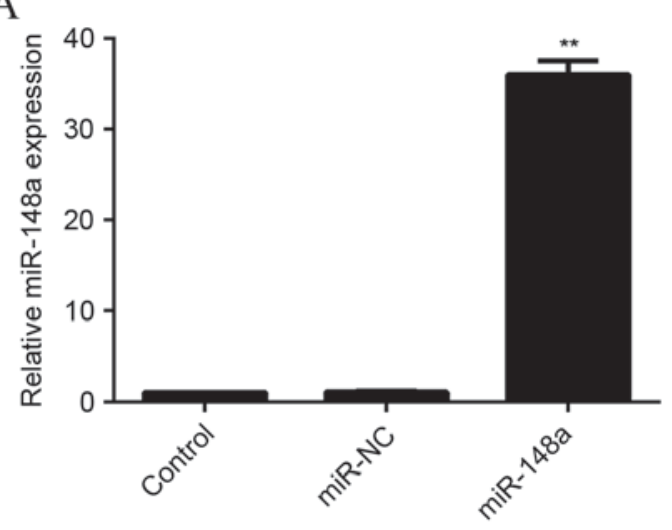

C Control miR-NC miR-148a
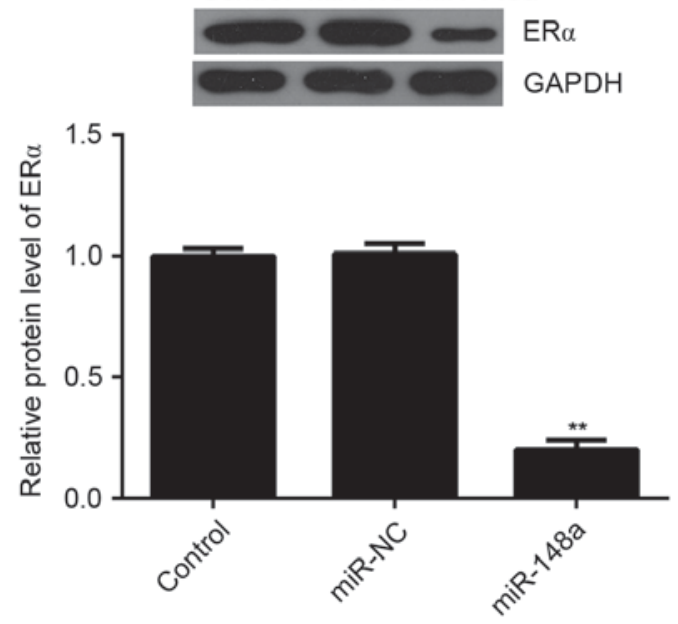

E

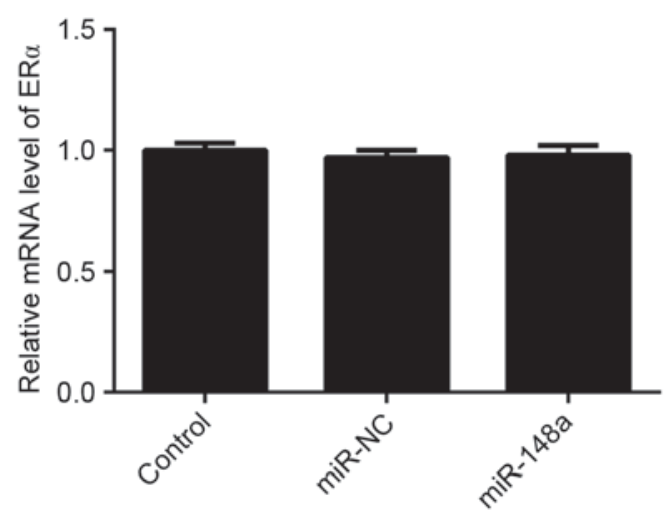

B

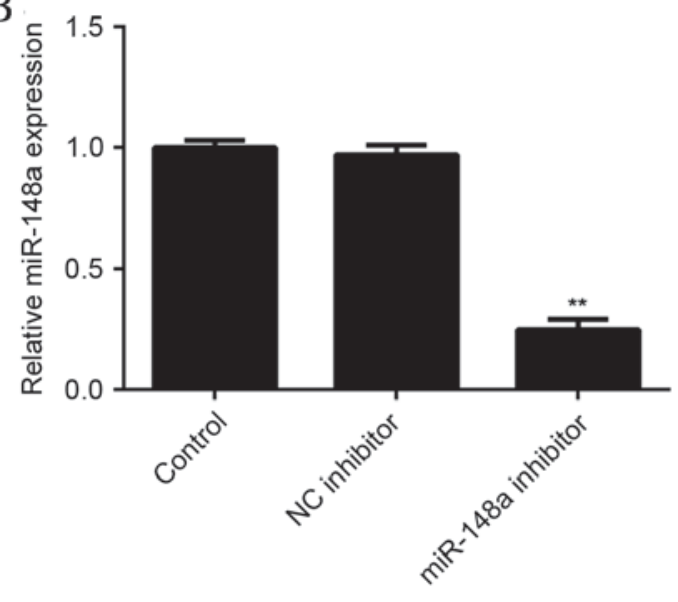

$\mathrm{D}$ Control inhibitor inhibitor
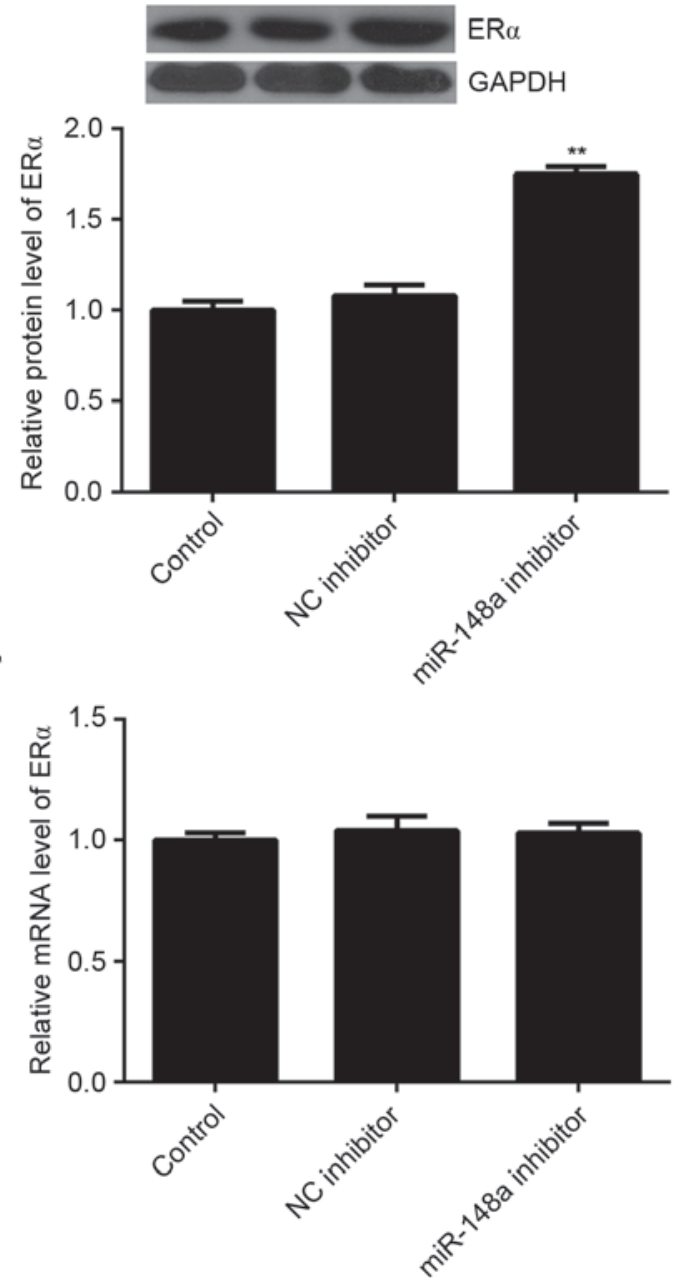

Figure 3. Effect of miR-148a on ER $\alpha$ protein expression in MCF7 cells. (A and B) Using qPCR, the miR-148a level was evaluated in MCF7 cells transfected with miR-NC, miR-148a mimic, NC inhibitor or miR-148a inhibitor. (C and D) Western blot analysis and (E and F) qPCR were used to evaluate the protein and mRNA expression of ER $\alpha$. Non-transfected MCF7 cells were used as the control. ${ }^{* *} \mathrm{P}<0.01$ vs. control. ER $\alpha$, estrogen receptor $\alpha$; NC, negative control; miR, microRNA; miR-NC, scrambled miR mimic; qPCR, quantitative polymerase chain reaction.

reduced miR-158a expression as compared with a dosage of $1 \mathrm{mM}$. These results suggest that E2 treatment decreases miR-148a expression, which increases the ER $\alpha$ protein level in MCF7 cells. Through activation of ER $\alpha$-mediated downstream signaling, E2 treatment induces the viability and migration of breast cancer cells.

\section{Discussion}

The present study investigated the function and underlying mechanism of miR-148a in mediating the E2-induced viability and migration of ER $\alpha$-positive breast cancer MCF7 cells. The results showed that treatment with E2 significantly enhanced 
A

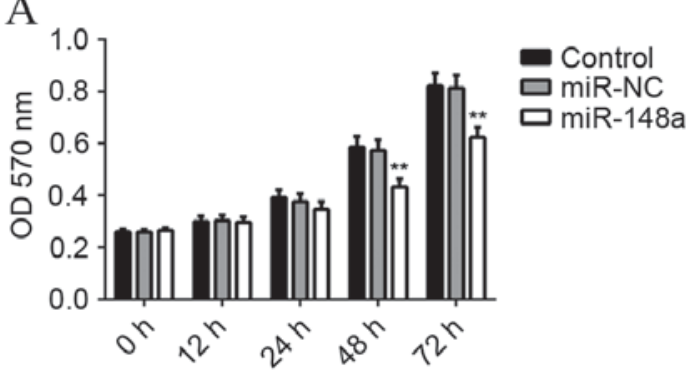

C
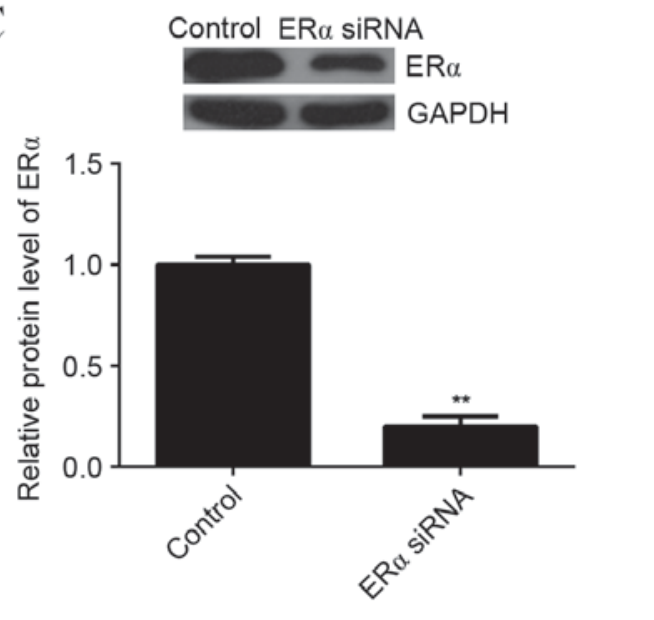

B
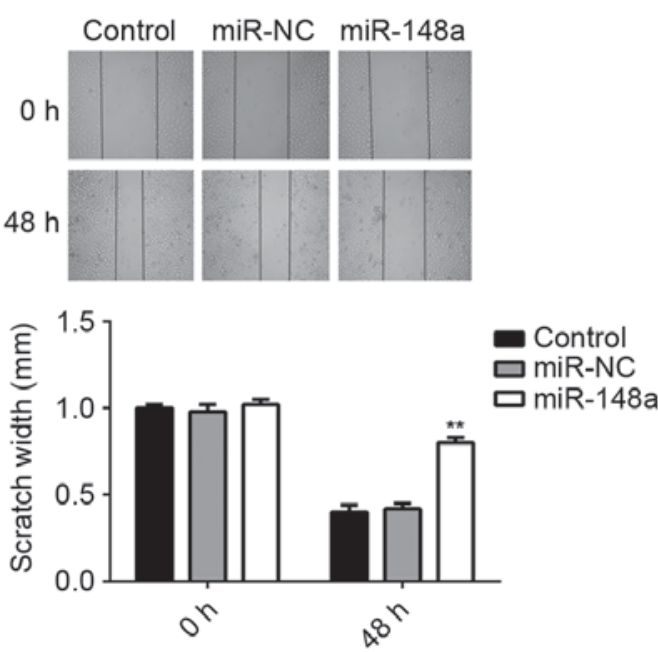

D

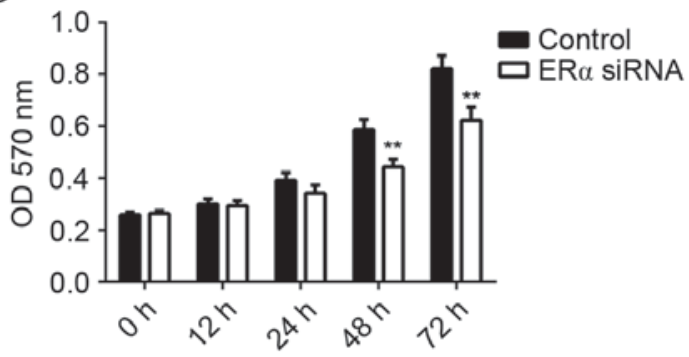

E
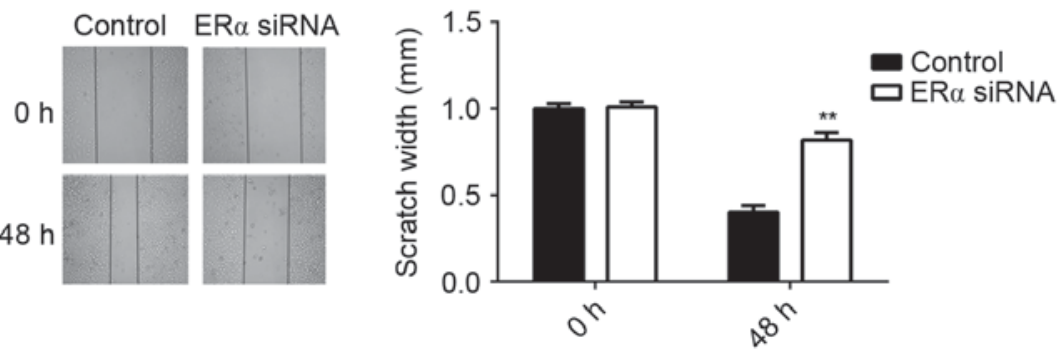

Figure 4. Effect of miR-148a overexpression or ER $\alpha$ knockdown on E2-induced MCF7 cell viability and migration. MCF7 cells transfected with miR-NC or miR-148a mimic were treated with E2 for $3 \mathrm{~h}$. (A) MTT assay and (B) wound healing assay were used to determine the cell viability and migration, respectively. (C) MCF7 cells were transfected with ER $\alpha$-specific siRNA, and western blot analysis was used to evaluate the protein expression of ER $\alpha$. Then, MCF7 cells with or without ER $\alpha$ knockdown were treated with E2 for 3 h. (D) MTT assay and (E) wound healing assay were used to determine the cell viability and migration, respectively. Non-transfected MCF7 cells were used as the control. ${ }^{* *} \mathrm{P}<0.01$ vs. control. ER $\alpha$, estrogen receptor $\alpha$; E2, estradiol; miR, microRNA; siRNA; small interfering RNA; miR-NC, scrambled miR mimic.

the viability and migration of MCF7 cells. miR-148a was found to negatively regulate the protein expression of ER $\alpha$ in MCF7 cells through directly binding to the 3'UTR of ER $\alpha$ mRNA and thus causing translation inhibition. Ectopic expression of miR-148a significantly suppressed the E2-induced viability and migration of MCF7 cells, similar to the effect of ER $\alpha$ knockdown. Furthermore, overexpression of ER $\alpha$ rescued the suppressive effect of miR-148a on E2-induced viability and migration of MCF7 cells. Finally, treatment with E2 was found to suppress miR-148a expression in MCF7 cells in a dose-dependent manner.

ER $\alpha$, coded by gene ESR1, is a ligand-activated transcription factor composed of several domains important for hormone binding, DNA binding and activation of transcription (24). ER $\alpha$ localizes to the nucleus where it may form a homodimer or a heterodimer with $\operatorname{ER} \beta$ (25). It has previously been demonstrated that E2 and ER $\alpha$ are essential for sexual development and reproductive function, and are involved in some human cancers such as breast cancer and endometrial cancer (26-28). In the present study, treatment with E2 promoted the viability and migration of ER $\alpha$-positive breast cancer MCF7 cells. Therefore, the E2/ER $\alpha$-mediated signaling pathway is a promising target in the treatment of ER $\alpha$-positive breast cancer. Shang et al demonstrated that baicalein could inhibit E2-induced migration, adhesion and invasion of breast cancer cells via the G-protein-coupled receptor 30 signaling pathway (29).

Furthermore, treatment with E2 has previously been found to cause deregulation of many miRs during the mammary carcinogenesis process (30), suggesting that miRs may play a role in breast cancer. For instance, miR-125b was found to be significantly upregulated in breast cancer, and its upregulation was associated with poor prognosis and aromatase inhibitor resistance (31). miR-200b was reported to be downregulated 
A miR-148a miR-148a+ER $\alpha$

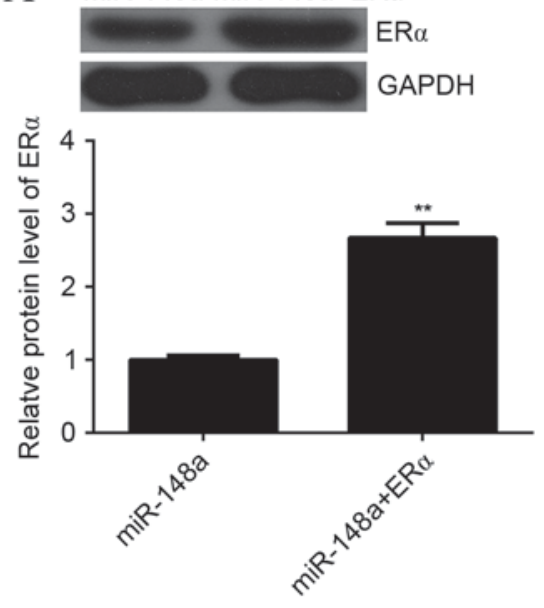

\section{B}

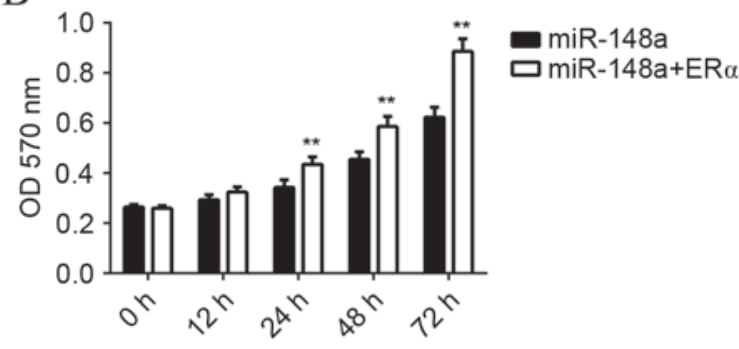

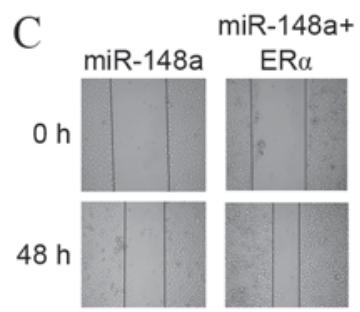

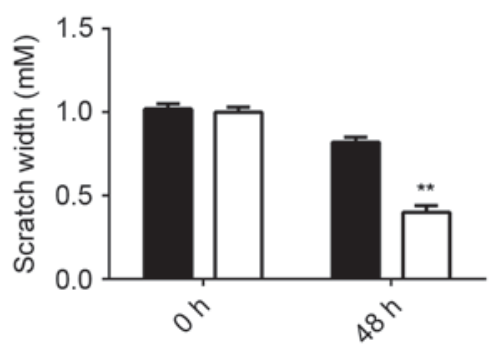

miR-148a

$\square \mathrm{miR}-148 \mathrm{a}+\mathrm{ER} \alpha$

Figure 5. Effect of miR-148a on E2-induced MCF7 cell viability and migration via inhibition of ER $\alpha$ expression. (A) MCF7 cells were co-transfected with miR-148a mimic and ER $\alpha$ ORF plasmid, and western blot analysis was used to evaluate the protein expression of ER $\alpha$. Next, MCF7 cells were treated with E2 for $3 \mathrm{~h}$. (B) MTT and (C) wound healing assays were used to determine cell viability and migration, respectively. miR-148a-overexpressing MCF7 cells were used as the control. ${ }^{* *} \mathrm{P}<0.01$ vs. miR-148a. ER $\alpha$, estrogen receptor $\alpha$; E2, estradiol; miR, microRNA.

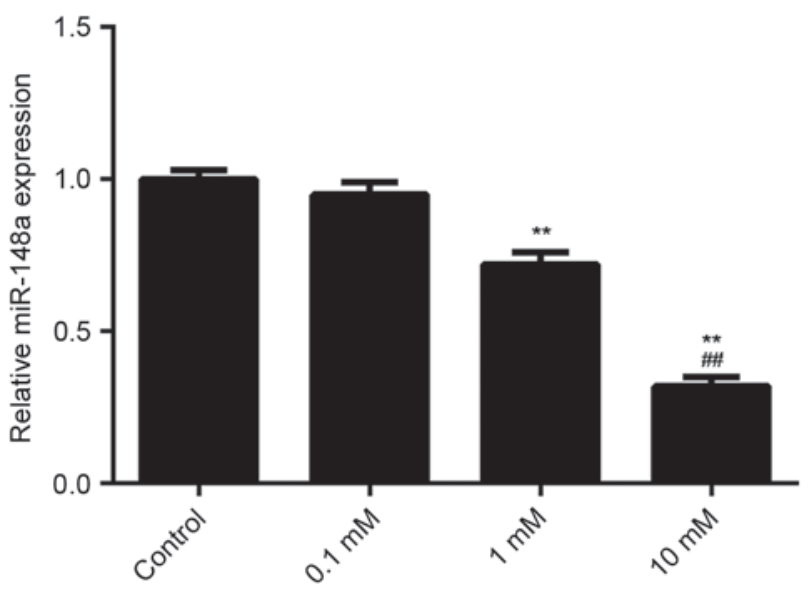

Figure 6. Effect of E2 treatment on the expression of miR-148a in MCF7 cells. (A) Using, qPCR, the expression levels of miR-148a were evaluated in MCF7 cells treated with E2 of different concentrations $(0.1,1$ or $10 \mathrm{mM})$ for $3 \mathrm{~h}$. Non-treated MCF7 cells were used as the control. ${ }^{* * *} \mathrm{P}<0.01$ vs. control.

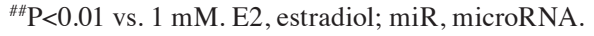

in breast cancer, and its low expression was correlated with late Tumor, Node, Metastasis stages, negative ER and positive HER-2 statuses, and poor prognosis (32).

miR-148a has been demonstrated to serve a suppressive function in multiple cancer types $(33,34)$. For instance, miR-148a was downregulated in gastric cancer due to hypermethylation in its promoter region (35). Furthermore, miR-148a was found to regulate numerous target genes and pathways involving tumor proliferation, invasion and metastasis (35). It is also significantly downregulated in non-small cell lung cancer (NSCLC) compared to adjacent non-cancerous lung tissues, and its low level is significantly associated with lymph-node metastasis (36). In addition, it can suppress epithelial-to-mesenchymal transition by targeting ROCK1 in NSCLC cells (36). In the present study, ER $\alpha$ was found to be a direct target gene of miR-148a, and its expression was negatively regulated by miR-148a at the post-transcriptional level in MCF7 cells. To further reveal the role of miR-148a in ER $\alpha$-positive breast cancer, MCF7 cells were transfected with miR-148a mimic to increase its expression level. Overexpression of miR-148a suppressed the E2-induced viability and migration of MCF7 cells. Moreover, siRNA-induced ER $\alpha$ downregulation also inhibited the E2-induced MCF7 cell viability and migration, similar to the effect of miR-148a upregulation. These results suggested that miR-148a affected the E2-induced MCF7 cell viability and migration through inhibiting the protein expression of ER $\alpha$. To verify this, ER $\alpha$ ORF plasmid was transfected into miR-148a-overexpressing MCF7 cells. The resulting overexpression of ER $\alpha$ reversed the suppressive effect of miR-148a effect on E2-induced MCF7 cell viability and migration. Therefore, ER $\alpha$ has been demonstrated to be involved in the miR-148a-mediated viability and migration of MCF7 cells treated with E2.

In addition, it was found that treatment with E2 decreased the miR-148a levels in MCF7 cells in a dose-dependent manner. This indicated that E2 treatment not only activates the ER $\alpha$-mediated viability and migration-related signaling 
in MCF7 cells, but also increases the ER $\alpha$ protein level via inhibition of miR-148a expression.

In conclusion, the present study demonstrates that miR-148a inhibits the E2-induced viability and migration of ER $\alpha$-positive breast cancer cells, at least partly via inhibition of ER $\alpha$ protein expression. These findings expand the understanding of miR function in breast cancer, and suggest that miR-148a is a promising candidate for the treatment of ER $\alpha$-positive breast cancer.

\section{Acknowledgements}

This study was supported by the National Basic Research Program of China (grant no. +2013CB835100 to Dr Lingjiang Li), the Projects of the Science and Technology Department of Hunan Province (grant no. 2011FJ6043) and the Health Department of Hunan Province (grant no. B2011-017).

\section{References}

1. Torre LA, Bray F, Siegel RL, Ferlay J, Lortet-Tieulent J and Jemal A: Global cancer statistics, 2012. CA Cancer J Clin 65 87-108, 2015

2. Siegel R, Naishadham D and Jemal A: Cancer statistics, 2013. CA Cancer J Clin 63: 11-30, 2013.

3. Jemal A, Bray F, Center MM, Ferlay J, Ward E and Forman D: Global cancer statistics. CA Cancer J Clin 61: 69-90, 2011.

4. Segovia-Mendoza M, González-Gonzalez ME, Barrera D, Díaz L and García-Becerra R: Efficacy and mechanism of action of the tyrosine kinase inhibitors gefitinib, lapatinib and neratinib in the treatment of HER2-positive breast cancer: Preclinical and clinical evidence. Am J Cancer Res 5: 2531-2561, 2015.

5. Das Gupta S, Sae-Tan S, Wahler J, So JY, Bak MJ, Cheng LC, Lee MJ, Lin Y, Shih WJ, Shull JD, Safe S, et al: Dietary $\gamma$-Tocopherol rich mixture inhibits estrogen-induced mammary tumorigenesis by modulating estrogen metabolism, antioxidant response and PPAR $\gamma$. Cancer Prev Res (Phila) 8: 807-816, 2015.

6. Thomas C and Gustafsson JA: Estrogen receptor mutations and functional consequences for breast cancer. Trends Endocrinol Metab 26: 467-476, 2015.

7. Xu B, Lovre D and Mauvais-Jarvis F: Effect of selective estrogen receptor modulators on metabolic homeostasis. Biochimie 124: 92-97, 2016.

8. Misawa A and Inoue S: Estrogen-related receptors in breast cancer and prostate cancer. Front Endocrinol (Lausanne) 6:83, 2015.

9. Xiong R, Patel HK, Gutgesell LM, Zhao J, Delgado-Rivera L, Pham TN, Zhao H, Carlson K, Martin T, Katzenellenbogen JA, et al: Selective human estrogen receptor partial agonists (ShERPAs) for tamoxifen-resistant breast cancer. J Med Chem 59: 219-237, 2016.

10. Kaaks R, Lukanova A and Kurzer MS: Obesity, endogenous hormones, and endometrial cancer risk: A synthetic review. Cancer Epidemiol Biomarkers Prev 11: 1531-1543, 2002.

11. Fan P, Maximov PY, Curpan RF, Abderrahman B and Jordan VC: The molecular, cellular and clinical consequences of targeting the estrogen receptor following estrogen deprivation therapy. Mol Cell Endocrinol 418: 245-263, 2015.

12. Ambros V: The functions of animal microRNAs. Nature 431: 350-355, 2004

13. John B, Enright AJ, Aravin A, Tuschl T, Sander C and Marks DS: Human MicroRNA targets. PLoS Biol 2: e363, 2004.

14. Calin GA and Croce CM: MicroRNA signatures in human cancers. Nat Rev Cancer 6: 857-866, 2006.

15. Boukerroucha M, Josse C, ElGuendi S, Boujemla B, Frères P, Marée R, Wenric S, Segers K, Collignon J, Jerusalem G and Bours V: Evaluation of BRCA1-related molecular features and microRNAs as prognostic factors for triple negative breast cancers. BMC Cancer 15: 755, 2015.
16. Kehl KL, Shen C, Litton JK, Arun B and Giordano SH: Rates of BRCA1/2 mutation testing among young survivors of breast cancer. Breast Cancer Res Treat 155: 165-173, 2016.

17. Yu J, Li Q, Xu Q, Liu L and Jiang B: MiR-148a inhibits angiogenesis by targeting ERBB3. J Biomed Res 25: 170-177, 2011.

18. Aydogdu E, Katchy A, Tsouko E, Lin CY, Haldosén LA, Helguero L and Williams C: MicroRNA-regulated gene networks during mammary cell differentiation are associated with breast cancer. Carcinogenesis 33: 1502-1511, 2012.

19. Jiang Q, He M, Ma MT, Wu HZ, Yu ZJ, Guan S, Jiang LY, Wang Y, Zheng DD, Jin F and Wei MJ: MicroRNA-148a inhibits breast cancer migration and invasion by directly targeting WNT-1. Oncol Rep 35: 1425-1432, 2016.

20. Xue J, Chen Z, Gu X, Zhang Y and Zhang W: MicroRNA-148a inhibits migration of breast cancer cells by targeting MMP-13. Tumour Biol 37: 1581-1590, 2016.

21. Soltani S, Mokarian F and Panjehpour M: The expression of CK-19 gene in circulating tumor cells of blood samples of metastatic breast cancer women. Res Pharm Sci 10: 485-496, 2015.

22. Agarwal V, Bell GW, Nam JW and Bartel DP: Predicting effective microRNA target sites in mammalian mRNAs. Elife 4: e05005, 2015.

23. Schröder L, Koch J, Mahner S, Kost BP, Hofmann S, Jeschke U, Haumann J, Schmedt J and Richter DU: The effects of petroselinum crispum on estrogen receptor-positive benign and malignant mammary cells (MCF12A/MCF7). Anticancer Res 37: 95-102, 2017.

24. Murphy E: Estrogen signaling and cardiovascular disease. Circ Res 109: 687-696, 2011.

25. Matthews J and Gustafsson JA: Estrogen signaling: A subtle balance between ER alpha and ER beta. Mol Interv 3: 281-292, 2003.

26. Anbalagan M and Rowan BG: Estrogen receptor alpha phosphorylation and its functional impact in human breast cancer. Mol Cell Endocrinol 418: 264-272, 2015.

27. Bondesson M, Hao R, Lin CY, Williams C and Gustafsson J Estrogen receptor signaling during vertebrate development. Biochim Biophys Acta 1849: 142-151, 2015.

28. Chan S: A review of selective estrogen receptor modulators in the treatment of breast and endometrial cancer. Semin Oncol 29 (3 Suppl 11): S129-S133, 2002.

29. Shang D, Li Z, Zhu Z, Chen H, Zhao L, Wang $X$ and Chen Y: Baicalein suppresses 17- $\beta$-estradiol-induced migration, adhesion and invasion of breast cancer cells via the $G$ protein-coupled receptor 30 signaling pathway. Oncol Rep 33: 2077-2085, 2015.

30. Munagala R, Aqil F, Vadhanam MV and Gupta RC: MicroRNA 'signature' during estrogen-mediated mammary carcinogenesis and its reversal by ellagic acid intervention. Cancer Lett 339: 175-184, 2013.

31. Vilquin P, Donini CF, Villedieu M, Grisard E, Corbo L, Bachelot T, Vendrell JA and Cohen PA: MicroRNA-125b upregulation confers aromatase inhibitor resistance and is a novel marker of poor prognosis in breast cancer. Breast Cancer Res 17: 13, 2015.

32. Yao Y, Hu J, Shen Z, Yao R, Liu S, Li Y, Cong H, Wang X, Qiu W and Yue L: MiR-200b expression in breast cancer: A prognostic marker and act on cell proliferation and apoptosis by targeting Sp1. J Cell Mol Med 19: 760-769, 2015.

33. Chen Y, Song YX and Wang ZN: The microRNA-148/152 family: Multi-faceted players. Mol Cancer 12: 43, 2013.

34. Takahashi M, Cuatrecasas M, Balaguer F, Hur K, Toiyama Y, Castells A, Boland CR and Goel A: The clinical significance of MiR-148a as a predictive biomarker in patients with advanced colorectal cancer. PLoS One 7: e46684, 2012.

35. Xia J, Guo X, Yan J and Deng K: The role of miR-148a in gastric cancer. J Cancer Res Clin Oncol 140: 1451-1456, 2014.

36. Li J, Song Y, Wang Y, Luo J and Yu W: MicroRNA-148a suppresses epithelial-to-mesenchymal transition by targeting ROCK1 in non-small cell lung cancer cells. Mol Cell Biochem 380: 277-282, 2013. 